\title{
Physical-chemical characteristics of whitening toothpaste and evaluation of its effects on enamel roughness
}

\section{Sérgio Paulo Hilgenberg ${ }^{(a)}$ Shelon Cristina Souza Pinto(a) Paulo Vitor Farago ${ }^{(b)}$ Fábio André Santos(a) Denise Stadler Wambier ${ }^{(a)}$}

\footnotetext{
(a) Department of Dentistry, School of Dentistry, Ponta Grossa State University, Ponta Grossa, PR, Brazil.

(b) Department of Pharmacy, School of Dentistry, Ponta Grossa State University, Ponta Grossa, PR, Brazil.
}

\begin{abstract}
This in vitro study evaluated the physical-chemical characteristics of whitening toothpastes and their effect on bovine enamel after application of a bleaching agent ( $16 \%$ carbamide peroxide). Physical-chemical analysis was made considering mass loss by desiccation, ash content and $\mathrm{pH}$ of the toothpastes. Thirty bovine dental enamel fragments were prepared for roughness measurements. The samples were subjected to bleaching treatments and simulated brushing: G1. Sorriso Dentes Brancos (Conventional toothpaste), G2. Close-UP Whitening (Whitening toothpaste), and G3. Sensodyne Branqueador (Whitening toothpaste). The average roughness $(\mathrm{Ra})$ was evaluated prior to the bleaching treatment and after brushing. The results revealed differences in the physical-chemical characteristics of the toothpastes $(\mathrm{p}<0.0001)$. The final Ra had higher values $(\mathrm{p}<0.05)$ following the procedures. The mean of the Ra did not show significant differences, considering toothpaste groups and bleaching treatment. Interaction (toothpaste and bleaching treatment) showed significant difference $(\mathrm{p}<0.0001)$. The whitening toothpastes showed differences in their physical-chemical properties. All toothpastes promoted changes to the enamel surface, probably by the use of a bleaching agent.
\end{abstract}

Descriptors: Dentifrices; Tooth bleaching; Toothbrushing; Dental Enamel.

\section{Introduction}

Patients increasingly seek to have an attractive smile, as it is considered to be synonymous with health. ${ }^{1-2}$ This growing demand for an enhanced esthetic appearance has led to great development of bleaching products. $^{3-5}$ The color of teeth is influenced by a combination of their intrinsic color and the presence of any extrinsic stains that may form on the tooth surface. ${ }^{6}$

The active components of the whitening toothpastes include surfactants, polyphosphates and enzymes. Some of them also contain low peroxide concentrations. However, the evidence to date suggests that the primary stain removal ingredient in these toothpastes is the abrasive agents. ${ }^{4,6}$

The abrasive agents are present in the toothpastes' formulation, which play an important role in cleaning teeth. However, their abrasiveness, which is influenced by particle hardness, size and shape, and also by the $\mathrm{pH}$ of the toothpaste, must be controlled. High amounts of abrasives in
Received for publication on Feb 25, 2011 Accepted for publication on May 23, 2011
Corresponding author:

Denise Stadler Wambier

E-mail: dswambier@yahoo.com.br 
toothpastes may damage hard and soft tissues and dental restorations, leading to gingival recession, cervical abrasion and dentinal hypersensitivity. ${ }^{2-3,5}$, ${ }^{7-12}$ In order to ensure their effectiveness, they must have physical-chemical characteristics that allow for their therapeutic action without damaging oral tissues. ${ }^{13}$ Fluorine, the soluble element present in toothpastes, is able to combine with abrasive agents, rendering it insoluble and unable to exert its remineralizing property. ${ }^{1,9,12,14}$

Considering the whitening toothpastes, their daily use should be subject to several considerations; e.g., after the consumption of acid beverages, a high concentration of abrasives may lead to increased wear of enamel and dentine. The concomitant use of abrasive toothpastes during at-home bleaching procedures reportedly increases the roughness of dental enamel. ${ }^{11,15-18}$

The purpose of this study was to evaluate the physical-chemical characteristics of the whitening toothpastes by determining their effect on bovine enamel surfaces during brushing after treatment by a bleaching agent. The classical alternative hypothesis that was investigated was: the composition of the tested toothpastes does not interfere with enamel surface roughness after the bleaching treatment.

\section{Methodology}

\section{Physical-chemical analysis}

All the analyses were conducted in quintuplicate, and the tested toothpastes were divided into three groups:

- Group 1 (G1. Conventional toothpaste: Sorriso Dentes Brancos $\left.{ }^{\circledR}\right)$,

- Group 2 (G2. Whitening toothpaste: Close-UP Whitening $\left.{ }^{\circledR}\right)$, and
- Group 3 (G3. Whitening toothpaste: Sensodyne Branqueador $^{\circledR}$ ) (Table 1).

\section{Desiccation loss and residue analysis}

The toothpastes were weighed on a Petri dish $(5.0$ grams) and heated in an oven at $105^{\circ} \mathrm{C}$ for 24 hours. They were then weighed again, repeating this process until the same weight was recorded in consecutive checks. Loss by desiccation was calculated from the difference between the initial and final weights.

\section{pH analysis}

The $\mathrm{pH}$ was measured using a digital potentiometer (DMPH-2, Digimed; São Paulo, Brazil). Measurements were performed only once for each sample at a dilution of 5.0 grams suspended in $15 \mathrm{~mL}$ of distilled water.

\section{Scanning Electron Microscope (SEM)}

After the toothpastes were desiccated, they were placed in porcelain crucibles and heated in a furnace at $650{ }^{\circ} \mathrm{C}$ to produce ashes, which were then analyzed under a SEM (Shimadzu SSX 550, Shimadzu do Brasil, São Paulo, Brazil), operated at $15 \mathrm{kV}$ at $1000 \times$ magnification.

\section{Evaluation of the enamel surface}

\section{Preparation of the dental fragments}

The specimens were prepared from freshly extracted bovine incisors stored in artificial saliva. The vestibular portion of the dental crown was sectioned vertically and horizontally (three and four times, respectively) to obtain fragments of $4 \times 4 \mathrm{~mm}$. These cuts were made using a water-cooled diamond saw (ISOMET 1000- Precision Saw Buehler, Lake Bluff, USA). In preparation for cutting, the teeth were

Table 1 - Toothpastes used in the study.

\begin{tabular}{|c|c|c|c|}
\hline Group & Toothpaste & Manufacturer & Active ingredients \\
\hline G1 & $\begin{array}{l}\text { Sorriso Dentes Brancos } \\
\text { (Conventional) }\end{array}$ & $\begin{array}{l}\text { Colgate - Palmolive do Brasil, } \\
\text { São Paulo, Brazil }\end{array}$ & $\begin{array}{l}\text { Fluoride, calcium carbonate, sodium lauryl sulfate, tetrasodium } \\
\text { pyrophosphate and sodium silicate }\end{array}$ \\
\hline G2 & $\begin{array}{l}\text { Close-UP Whitening } \\
\text { (Whitening) }\end{array}$ & $\begin{array}{c}\text { Unilever do Brasil; São Paulo, } \\
\text { Brazil }\end{array}$ & Silica, perlite, sodium lauryl sulfate, sodium fluoride and titanium dioxide \\
\hline G3 & $\begin{array}{l}\text { Sensodyne Branqueador } \\
\text { (Whitening) }\end{array}$ & $\begin{array}{l}\text { GlaxoSmithKline do Brasil, } \\
\text { São Paulo, Brazil }\end{array}$ & $\begin{array}{c}\text { Potassium nitrate, sodium fluoride, silica, sodium bicarbonate, titanium } \\
\text { dioxide and pyrophosphate tetrapotassium }\end{array}$ \\
\hline
\end{tabular}


mounted on an aluminum support using sticky wax (Figure 1A). Six enamel fragments were obtained from each bovine tooth (Figure 1B). The fragments were converted into test specimens comprising three units each. The enamel samples were embedded in acrylic autopolymerizable resin, leaving the vestibular enamel surface exposed. Thirty test specimens were prepared ( $\mathrm{n}=10$, per group). The power calculation was performed using data from a previous pilot study (unpublished). If the sample size in each of the 3 groups (toothpaste) is 10 there would be $90 \%$ power for average roughness to detect a difference of $5 \%$. The common standard deviation was 0.27 at an effect size of 0.48 and 0.05 level for a two-side test.

After the acrylic resin was embedded, the vestibular surfaces of the fragments were smoothed in a polishing machine (Aropol E; Arotec Ind. e Com. Ltda., São Paulo, Brazil). Aluminum oxide disks were used in sequential grit sizes of 400,600, and 1,000 , respectively, and then polished with a felt cloth in conjunction with abrasive pastes $6,3,1$, and $1 / 2 \mu \mathrm{m}$ along with a mineral oil coolant (Top, Gold, e Ram, Arotec Ind e Com Ltda., São Paulo, Brazil). These procedures were conducted in order to obtain homogeneous surfaces for treatment (Figure 1C).

\section{Roughness measurements prior to and after treatment}

After the samples were polished, initial enamel surface roughness parameters (initial and final) were obtained by a digital profilometer (Surftest 301, Mitutoyo Sul Americana, Suzano, Brazil). The profilometer was set for a sampling surface of $1.25 \mathrm{~mm}$, with a cutoff value of $0.25 \mathrm{~mm}$. Two points in each fragment of enamel were measured to obtain the initial roughness values for the enamel surface. This measurement was carried out transversely to the direction in which the fragment would be brushed. Thus, the average roughness ( $\mathrm{Ra})$ was obtained. After treatment of the test specimens following the same procedure, the roughness was evaluated again (final roughness).

\section{Bleaching treatment and brushing with toothpastes}

The first enamel fragment was treated with 16\% carbamide peroxide bleaching agent (Whiteness Perfect, FGM, Joinvile, Brazil) for a period of 10 hours. The second fragment was treated with the same bleaching agent for the same period of time, and it also received a 1-min topical application of 2\% neutral fluoride gel (Flugel, DFL, Jacarepaguá, Brazil). The third enamel fragment was treated with artificial saliva. After treatment, the enamel samples were brushed using the tested toothpastes.

The simulated brushing using the toothpastes and application of bleaching agent and fluoride were carried out 4 times. Each simulation comprised
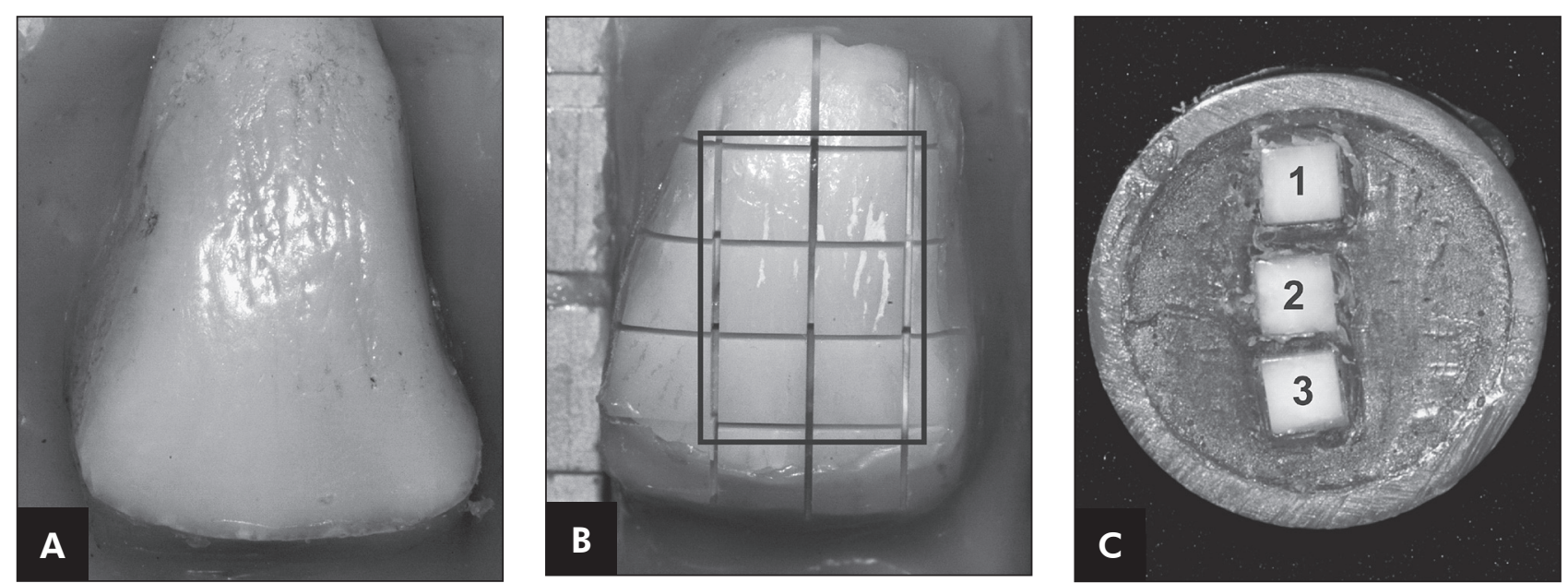

Figure 1 - (A) Bovine tooth inserted into an aluminum base with sticky wax. (B) Six enamel fragments $(4 \times 4 \mathrm{~mm})$ were obtained from each bovine tooth. (C) Fragments of enamel embedded in acrylic resin were smoothed in a polishing machine: 1 - Bleaching; 2 - Bleaching + Fluoride; 3 - Saliva. 
400 cycles (back and forth movements). Simulated brushing was carried out under a load of $200 \mathrm{~g}$ in a universal brushing machine (MSEt - 1500W, Marcelo Nucci ME; São Carlos, Brazil), using a toothbrush $(32 \mathrm{~mm} \times 11 \mathrm{~mm}$ head; $3 \times 9$ rows of tufts; soft artificial nylon bristles with rounded tips).

The toothpastes were diluted in distilled water at a ratio of $1: 2$ by weight, taken up in syringes and taken to the brushing machine. The machine was set to inject $2 \mathrm{ml}$ of the diluted toothpaste at 10 -second intervals, at a speed of 4.5 cycles per second. Each simulated brushing was carried out during the daytime, after which the samples were again immersed in artificial saliva at $37( \pm 1)^{\circ} \mathrm{C}$.

All laboratory procedures were conducted by two researchers.

\section{Statistical analysis}

Physical-chemical characteristics of the toothpastes (desiccation loss, ash content and $\mathrm{pH}$ tests) were evaluated by one-way ANOVA with Bonferroni's post-hoc test. Comparisons between the toothpastes and bleaching treatment for the final roughness were tested by two-way ANOVA with Bonferroni's post-hoc test. The initial and final roughness values found for each group were compared by paired Student's $t$-test. An alpha value of $\leq 0.05$ was used to indicate statistically significant differences among the groups. All analyses were performed using a software program (GraphPad Prism 5.00, GraphPad Software, San Diego, USA).

\section{Results \\ Physical-chemical characteristics of the toothpastes}

The results for percentage of desiccation loss, ash content and $\mathrm{pH}$ values revealed statistically significant differences $(\mathrm{p}<0.0001)$ among the groups (Table 2).

In the SEM evaluation, G2 and G3 displayed agglomerates of irregular particles that were sharptipped and of undefined shape, while G1 showed rounded and more clearly defined particles (Figure 2).
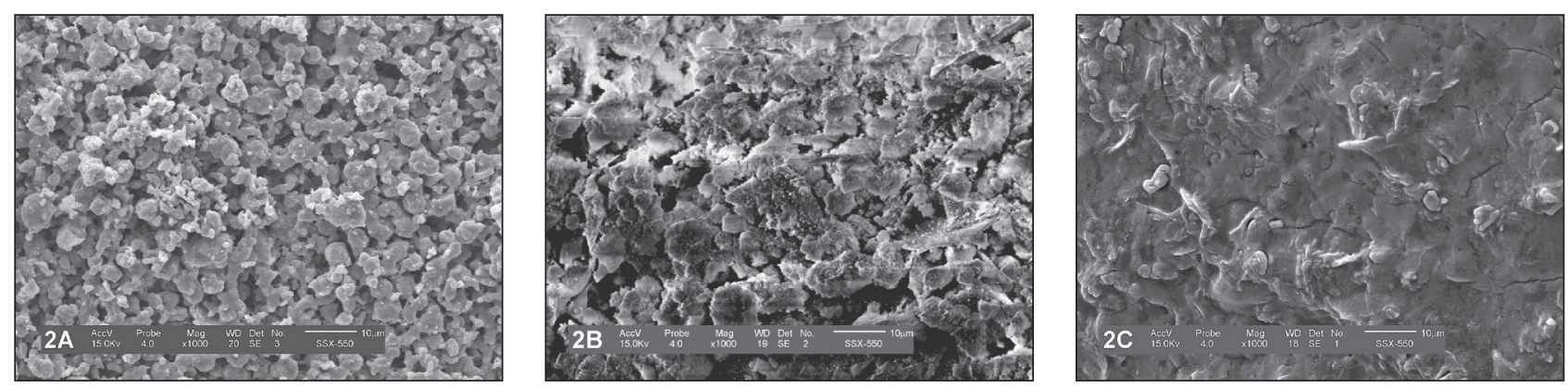

Figure 2 - SEM photomicrographs showing the toothpaste ashes. (A) Sorriso Dentes Brancos (G1. Conventional toothpaste), showing agglomeration of inorganic substances, round or oval-shaped and uniform. (B) Close-Up Whitening (G2. Whitening toothpaste). Presence of agglomeration of inorganic substances, sharp-tipped and amorphous. (C) Sensodyne Branqueador (G3. Whitening toothpaste); although the inorganic particles melted during calcination, irregular and amorphous particles are still visible. (bar $=10 \mu \mathrm{m})$.

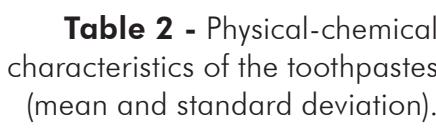

\begin{tabular}{c|c|c|c}
\hline Toothpaste & Loss by desiccation (\%) & Ash content (\%) & $\mathrm{pH}$ values \\
\hline $\begin{array}{c}\text { G1 - Conventional toothpaste } \\
\text { (Sorriso Dentes Brancos) }\end{array}$ & $31.91 \pm 1.12^{\mathrm{a}}$ & $36.67 \pm 1.97^{\mathrm{a}}$ & $10.09 \pm 0.14^{\mathrm{a}}$ \\
\hline $\begin{array}{c}\text { G2 - Whitening toothpaste } \\
\text { (Close-UP Whitening) }\end{array}$ & $44.73 \pm 1.12^{\mathrm{b}}$ & $17.64 \pm 1.23^{\mathrm{b}}$ & $7.87 \pm 0.08^{\mathrm{b}}$ \\
\hline $\begin{array}{c}\text { G3 - Whitening toothpaste } \\
\text { (Sensodyne Branqueador) }\end{array}$ & $65.83 \pm 2.21^{\mathrm{c}}$ & $16.00 \pm 3.09^{\mathrm{b}}$ & $9.12 \pm 0.16^{\mathrm{c}}$ \\
\hline
\end{tabular}

Vertically, different letters indicate statistically significant differences among bleaching treatments $(p<0.001)$. One-way ANOVA with Bonferroni's post-hoc test. 


\section{Analysis of enamel roughness}

The final average roughness $(\mathrm{Ra})$ had higher values following the bleaching treatment and brushing with toothpastes for G1 and G2. G3 showed statistical difference only following saliva treatment (Figure 3).

The mean of the Ra did not show statistically significant differences, considering toothpaste groups and bleaching treatment. Interaction (toothpaste and bleaching treatment) showed statistically significant difference (Table 3).

\section{Discussion}

The toothpastes that were studied showed different physical-chemical characteristics and changes on the enamel surface after treatments. Thus, the classical alternative hypothesis was rejected.

Several studies have evaluated the relation between the abrasive potential of toothpastes and alterations on enamel and restorative materials. ${ }^{2-3,8,14}$
However, the application of bleaching agents followed by brushing with abrasive toothpastes has not been extensively evaluated. , $^{3,7}, 17-18$

The desiccation loss test showed different values among the groups, indicating toothpastes with different compositions. G1 (Sorriso Dentes Brancos ${ }^{\circledR}$ ) presented the lowest loss by desiccation and the highest values of ash content (solid residues). This toothpaste, applied on the enamel surface increased the average roughness ( $\mathrm{Ra}$ ) parameter. The ash content and solid residues of toothpaste may determine its potential to alter the surface enamel, since higher values were a sign of alterations in roughness. ${ }^{13}$

Considering $\mathrm{pH}$, there were differences among the groups, but the $\mathrm{pH}$ in all of the three toothpastes was higher than 7 (neutral). An alkaline $\mathrm{pH}$ has a tendency to cause less change to the dental surface, while toothpastes with lower $\mathrm{pH}$ have showed greater alteration. On the other hand, in this study, G1 had the highest $\mathrm{pH}$ and promoted extensive

Figure 3 - Mean (standard error) of initial and final roughness parameter (Ra). Results of the paired Student's t-test for the three toothpastes after bleaching treatment (B. Bleaching; B/F. Bleaching + Fluoride; S. Saliva). *Significant difference $(p<0.05)$.

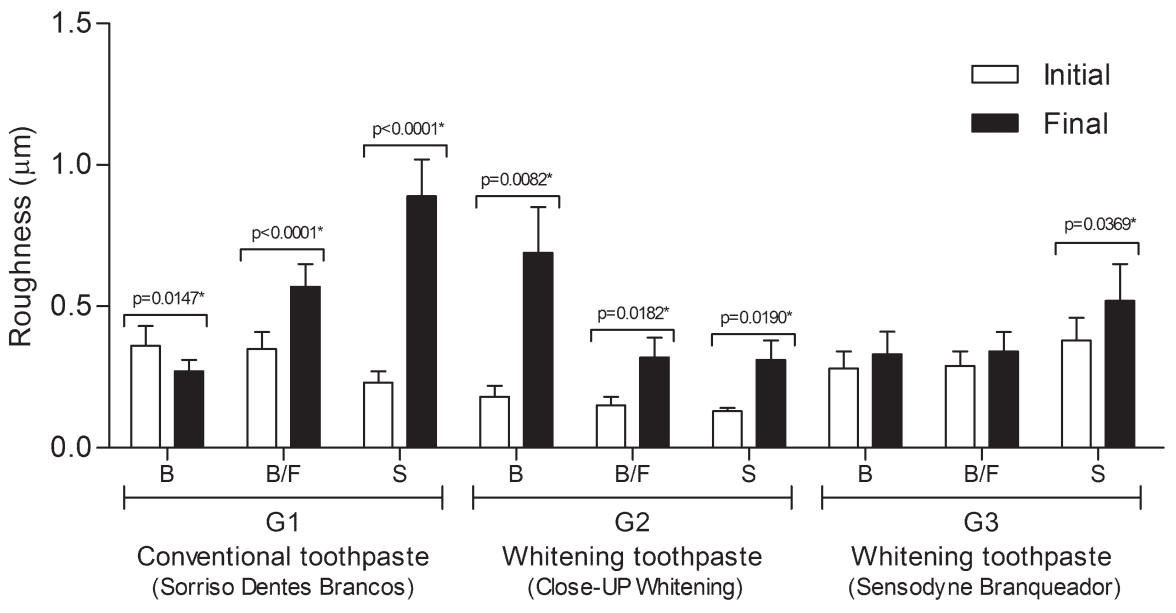

Table 3 - Mean and standard deviation of roughness parameter $(\mathrm{Ra})$ for bovine enamel following brushing with different toothpastes and bleaching treatments.

\begin{tabular}{c|c|c|c}
\hline \multirow{2}{*}{ Toothpaste } & \multicolumn{3}{|c}{ Bleaching Treatment } \\
\cline { 2 - 4 } & Bleaching & Bleaching/Fluoride & Saliva \\
\hline $\begin{array}{c}\text { G1 - Conventional toothpaste } \\
\text { (Sorriso Dentes Brancos) }\end{array}$ & $0.27 \pm 0.14^{\mathrm{Aa}}$ & $0.57 \pm 0.24^{\mathrm{Aa}}$ & $0.89 \pm 0.40^{\mathrm{Ba}}$ \\
\hline $\begin{array}{c}\mathrm{G} 2 \text { - Whitening toothpaste } \\
\text { (Close-UP Whitening) }\end{array}$ & $0.69 \pm 0.51^{\mathrm{Ab}}$ & $0.32 \pm 0.22 \mathrm{~B}^{\mathrm{Ba}}$ & $0.31 \pm 0.22^{\mathrm{Bb}}$ \\
\hline $\begin{array}{c}\text { G3 - Whitening toothpaste } \\
\text { (Sensodyne Branqueador) }\end{array}$ & $0.33 \pm 0.26^{\mathrm{Aa}}$ & $0.34 \pm 0.22^{\mathrm{Aa}}$ & $0.52 \pm 0.41^{\mathrm{Ab}}$ \\
\hline
\end{tabular}

Horizontally, different capital letters indicate statistically significant differences among bleaching treatments $(p<0.05)$. Vertically, different small letters indicate statistically significant differences among toothpastes $(p<0.05)$. Two-way ANOVA with Bonferroni's post-hoc test. 
change of the enamel surface. This finding suggests that the $\mathrm{pH}$ may be an important factor when considering the impact of the toothpaste on the enamel surface. $^{13}{ }^{15}$ G2 (Close-UP Whitening ${ }^{\circledR}$ ) presented a $\mathrm{pH}$ closest to 7 and altered the enamel surface when brushing was preceded by application of the bleaching agent.

The ash SEM analysis for G2 and G3 (Sensodyne Branqueador $^{\circledR}$ ) toothpastes revealed agglomerations of particles with irregular contours that were sharp tipped and often of irregular shape. G1 presented spherical agglomerated particles. These findings indicate that particle size also influences the effect of toothpaste on the dental surface. ${ }^{5,8,13}$

In this study, G1 was the only toothpaste whose composition contained calcium carbonate. Toothpastes with this composition are less abrasive. ${ }^{13}$ However, in the present research, G1 did not prove to be less abrasive. G2 (abrasive: silica) had resulted in an increase in roughness. Previous findings have shown that silica exhibits strong abrasive properties. ${ }^{8}$ Only in G3 (abrasive: sodium bicarbonate) did bleaching treatment prior to brushing not result in significant surface enamel alterations.

The application of a bleaching agent on the enamel structure is, per se, a factor that alters the surface characteristics. ${ }^{17}$ Different bleaching agents containing the same concentration of carbamide peroxide had different effects on dental enamel. ${ }^{18}$ Enamel chemical changes could be observed after $10 \%, 20 \%$ and $30 \%$ hydrogen peroxide treatment. ${ }^{16}$ In another study, enamel surface showed no mechanical, morphologic, or chemical changes following bleaching in situ with three different carbamide peroxide agents. ${ }^{19}$

Therefore, considering that the appropriate concentration of bleaching gel is still under discussion, in the present study only one concentration of carbamide peroxide $(16 \%)$ was used throughout the study for the sake of consistency.
Considering the initial and final roughness, the combination of whitening toothpaste and bleaching agent produced more changes to the enamel surface in G1 and G2.

Comparison of the final roughness between teeth brushed with the tested toothpastes and bleaching treatments did not show significant differences. Therefore, when the final roughness parameter data were grouped for statistical analysis (toothpastes and treatments), it was not possible to identify statistical differences, but the interaction (toothpaste and bleaching treatment) had shown statistically significant difference. Thus, the interaction factors were analyzed individually, showing significant difference between toothpastes after bleaching treatment. Toothpaste compositions could be responsible for different changes to the enamel surface. ${ }^{3-5,50-12}$

Fluoride's ability to form a protective film on the enamel surface has been established. ${ }^{1,7,9,14}$ However, the presence of fluoride in the bleaching gels did not increase mineral recovery. ${ }^{20}$ Similarly, in the present study, the application of fluoride gel for one minute after the bleaching agent did not add a protective effect. On the other hand, more studies are necessary about this subject.

\section{Conclusion}

Regarding physical-chemical characteristics, the whitening toothpastes showed higher loss by desiccation and lower ash content and $\mathrm{pH}$ values than the control group.

All toothpastes (whitening and control) were able to promote alterations to the enamel surface. The use of a bleaching agent before brushing with toothpaste could be a determining factor in the modifications revealed by the roughness parameter.

\section{Acknowledgements}

This work was supported by CAPES, Brazil. 


\section{References}

1. Altenburger MJ, Bernhart J, Schicha TD, Wrbas KT, Hellwig E. Comparison of in vitro fluoride uptake from whitening toothpastes and a conventional toothpaste in demineralised enamel. Schweiz Monatsschr Zahnmed. 2010;120(2):104-8.

2. Joiner A, Pickles MJ, Lynch S, Cox TF. The measurement of enamel wear by four toothpastes. Int Dent J. 2008 Feb;58(1):23-8.

3. Whitehead SA, Shearer AC, Watts DC, Wilson NH. Surface texture changes of a composite brushed with "tooth whitening” dentifrices. Dent Mater. 1996 Sep;12(5):315-8.

4. De Menezes M, Turssi CP, Hara AT, Messias DC, Serra MC. Abrasion of eroded root dentine brushed with different toothpastes. Clin Oral Investig. 2004 Sep;8(3):151-5.

5. Wulknitz P. Cleaning power and abrasivity of European toothpastes. Adv Dent Res. 1997 Nov;11(4):576-9.

6. Demarco FF, Meireles SS, Masotti AS. Over-the-counter whitening agents: a concise review. Braz Oral Res. 2009;23 (1 Suppl):64-70.

7. Magalhaes AC, Rios D, Delbem AC, Buzalaf MA, Machado MA. Influence of fluoride dentifrice on brushing abrasion of eroded human enamel: an in situlex vivo study. Caries Res. 2007;41(1):77-9.

8. Redmalm G. Dentifrice abrasivity. The use of laser light for determination of the abrasive properties of different silicas. An in vitro study. Swed Dent J. 1986;10(6):243-50.

9. Vieira A, Lugtenborg M, Ruben JL, Huysmans MC. Brushing abrasion of eroded bovine enamel pretreated with topical fluorides. Caries Res. 2006;40(3):224-30.

10. Kodaka T, Kobori M, Hirayama A, Abe M. Abrasion of human enamel by brushing with a commercial dentifrice containing hydroxyapatite crystals in vitro. J Electron Microsc (Tokyo). 1999;48(2):167-72.

11. Hooper S, West NX, Pickles MJ, Joiner A, Newcombe RG, Addy M. Investigation of erosion and abrasion on enamel and dentine: a model in situ using toothpastes of different abrasivity. J Clin Periodontol. 2003 Sep;30(9):802-8.
12. Kuroiwa M, Kodaka T, Kuroiwa M. Microstructural changes of human enamel surfaces by brushing with and without dentifrice containing abrasive. Caries Res. 1993;27(1):1-8.

13. Andrade Junior ACC, Andrade MRTC, Machado WAS, Fisher RG. [In vitro study of dentifrice abrasivity]. Rev Odontol Univ São Paulo. 1998 Jul-Set;12(3):231-6. Portuguese.

14. Vieira A, Ruben JL, Huysmans MC. Effect of titanium tetrafluoride, amine fluoride and fluoride varnish on enamel erosion in vitro. Caries Res. 2005 Sep-Oct;39(5):371-9.

15. Kielbassa AM, Gillmann L, Zantner C, Meyer-Lueckel H, Hellwig E, Schulte-Monting J. Profilometric and microradiographic studies on the effects of toothpaste and acidic gel abrasivity on sound and demineralized bovine dental enamel. Caries Res. 2005 Sep-Oct;39(5):380-6.

16. Paula SS, Soares LE, do Espirito Santo AM, Martin AA, Cavalli V, Liporoni PC. FT-Raman and energy dispersive X-ray fluorescence spectrometric analyses of enamel submitted to $38 \%$ hydrogen peroxide bleaching, an acidic beverage, and simulated brushing. Photomed Laser Surg. 2010 Jun;28(3):391-6.

17. Bitter NC. A scanning electron microscopy study of the effect of bleaching agents on enamel: a preliminary report. J Prosthet Dent. 1992 Jun;67(6):852-5.

18. Rodrigues JA, Basting RT, Serra MC, Rodrigues Junior AL. Effects of $10 \%$ carbamide peroxide bleaching materials on enamel microhardness. Am J Dent. 2001 Apr;14(2):67-71.

19. Smidt A, Feuerstein O, Topel M. Mechanical, morphologic, and chemical effects of carbamide peroxide bleaching agents on human enamel in situ. Quintessence Int. 2011 May;42(5):407-12.

20. Gabasso SP, Pinto CF, Cavalli V, Paes-Leme AF, Giannini M. Effect of fluoride-containing bleaching agents on bovine enamel microhardness. Braz J Oral Sci. 2011Jan-Mar;10(1):22-6. 